Article

\title{
Bioengineering Techniques Adopted for Controlling Riverbanks' Superficial Erosion of the Simplício Hydroelectric Power Plant, Brazil
}

\author{
Vinicius F. Vianna ${ }^{1}\left(\mathbb{D}\right.$, Mateus P. Fleury ${ }^{2, *}$ (D) Gustavo B. Menezes ${ }^{3}$, Arnaldo T. Coelho ${ }^{4}$, \\ Cecília Bueno ${ }^{5}$ (), Jefferson Lins da Silva ${ }^{2}$ and Marta P. Luz ${ }^{1,6}$ \\ 1 Eletrobras Furnas, Rio de Janeiro 22281-900, Brazil; viniciusvian@gmail.com (V.F.V.); \\ martaluz@furnas.com.br or marta.eng@pucgoias.edu.br (M.P.L.) \\ 2 São Carlos School of Engineering (EESC), University of São Paulo (USP), São Carlos 13566-590, Brazil; \\ jefferson@sc.usp.br \\ 3 Department of Civil Engineering, California State University, Los Angeles, CA 90032, USA; \\ gmeneze@calstatela.edu \\ 4 Ingá Engenharia e Consultoria, Belo Horizonte 30320-130, Brazil; arnaldo@ingaengenharia.com.br \\ 5 Biological Science and Professional Master in Environmental Sciences, Universidade Veiga de \\ Almeida (UVA), Rio de Janeiro 20271-020, Brazil; cecilia.bueno@uva.br \\ 6 Industrial and Systems Engineering Postgraduate Program (MEPROS), Pontifical Catholic University of \\ Goiás, Goiânia 74605-010, Brazil \\ * Correspondence: mateusfleury@usp.br; Tel.: +55-16-3373-8220
}

Received: 13 July 2020; Accepted: 17 September 2020; Published: 24 September 2020

\begin{abstract}
Controlling and preventing soil erosion on slope surfaces is a pressing concern worldwide, and at the same time, there is a growing need to incorporate sustainability into our engineering works. This study evaluates the efficiency of bioengineering techniques in the development of vegetation in soil slopes located near a hydroelectric power plant in Brazil. For this purpose, twelve different bioengineering techniques were evaluated, in isolation and in combination, in the slopes (10 $\mathrm{m} \mathrm{high}$ ) of two experimental units (approximately $70 \mathrm{~m}$ long each) located next to the Paraíba do Sul riverbanks, in Brazil. High-resolution images of the slopes' frontal view were taken in 15-day interval visits in all units for the first 90 days after implantation, followed by monthly visits up to 27 months after the works were finished. The images were treated and analyzed in a computer algorithm that, based on three-color bands (red-green-blue scale), helps to assess the temporal evolution of the vegetative cover index for each technique adopted. The results showed that most of the solutions showed a deficiency in vegetation establishment and were sensitive to climatological conditions, which induced changes in the vegetation phytosanitary aspects. Techniques which provided a satisfactory vegetative cover index throughout the investigated period are pointed out.
\end{abstract}

Keywords: bioengineering techniques; vegetative cover index; slope's superficial erosion; phytosanitary aspects; climatological conditions

\section{Introduction}

Soil erosion in slopes is a natural process that involves several processes such as landslides and detachment, dissolution and/or wear of soil particles, followed by their transport and deposition caused by the action of an erosive agent (e.g., water, wind, and/or gravity [1]). Human activities aggravate this process by removing existing vegetation, influencing agriculture and overstocked pasturing, and causing change in natural slopes by cutting operations routinely used in transportation works. This accelerated erosion shows relevant environmental, social, and economic impacts around 
the world, reducing soil fertility and promoting soil sedimentation in river flows [2]. Therefore, erosion control is a present concern and different techniques have been proposed over the last decades to address this issue, from hard engineering to more sustainable solutions, such as bioengineering $[3,4]$.

Bioengineering is an ancient technique that has recently regained interest and popularity for use in erosion control [5]. It combines live vegetation with or without inert components (e.g., rocks, wood, metal, geosynthetics, etc.) to reinforce soil, prevent and stabilize the erosion process, decrease surface runoff, and increase water infiltration, promoting ecosystem restoration [6-8]. The key aspect of this technique, according to Bischetti et al. [5], is that it is intentionally used considering an environmental and landscape perspective.

In a context with an increasing need to account for sustainability in engineering projects, bioengineering systems have clear advantages, because they show lower environmental impact compared to conventional stabilization methods that rely on hard structures such as retaining walls [2,9]. In this context, in Europe and North America, soil bioengineering has been widely used [10].

Research on soil bioengineering has experienced a significant increase over the last decades, leading to major advances over the past 20 years according to Stokes et al. [11], who highlight the relevance and interest of the scientific community [9]. Focus was given to the history and types of bioengineering techniques and applications [5,10,12-14], their technical, economic, environmental, and ecological benefits [15-19], the characterization of relevant physical and mechanical attributes of plant species application in such systems [20-22], and some successful case studies in transportation, urban settings, or riverbank restoration in the European Alps [23,24], North America [6,9,25], Central America [26], and South Asia $[15,27,28]$. The life cycle assessment (LCA) model for soil bioengineering constructions was also proposed [29].

In Brazil, the favorable climate to plant growth (especially the tropical one-characterized by a dry winter and rainy summer) supports the use of bioengineering techniques. However, few studies investigated the use of bioengineering systems in the Brazilian context, especially in large field test studies such as the one presented in this paper. Nonetheless, soil degradation is a major problem throughout the entire country [30]. Sattler et al. [31] highlight that the use of soil bioengineering in southeast Brazil (the economic pole of the country) for restoration and rehabilitation of degraded areas is still incipient, and when applied, relies mostly on the use of non-native plant species that have been shown to work in other tropical regions. After a 15-month monitoring period, the authors [31] reported successful riverbank slope protection when using hedgerow terraces (which work as living fences) with rooted or unrooted live cuttings of five native plant species (shrub or tree) associated with a biodegradable polymer.

Outside the Brazilian context, several studies reported the use of soil bioengineering techniques. Ansted et al. [29] monitored two willow spilling projects (used to prevent riverbank erosion) during the first year after installation to assess their biological and geomorphological function. Rey and Labonne [32] observed a 45\% survival rate of willow (Salix) cuttings (after four growing seasons) on bioengineering structures installed in the Francon Catchment (Southern French Alps). Brush layer inclusions were used to stabilize steep slopes along a roadway in Massachusetts [6]. Petrone and Preti [16] assessed which native species were most suited (survival rate higher than $60 \%$ ) for soil bio-engineering purposes in Nicaragua. Dhital and Tang [15] reported the effectiveness of vegetative check dams and wire net check dams along with vegetation in the stabilization of riverbanks located in Nepal. Furthermore, a laboratory study was carried out by Muhammed et al. [33].

Monitoring restored sites is as important as the planning stage of the restoration program. It can significantly influence the success of the solution used and provides invaluable data for future bioengineering projects, such as the lifetime and efficacy of the bioengineering system on slope stability and erosion control in different regions [2,34]. Nonetheless, studies on the ecological efficiency of slope restoration techniques are still scarce [15].

This study aims to assess the performance of 12 soil bioengineering techniques (systems) in erosion prone slopes of the Simplício Hydroelectric Power Plant-FURNAS in Brazil. We evaluated 
their viability and performance over 27 months after implantation. The latter was evaluated by periodic qualitative observations (integrity, anchoring, soil stability, germination, phytosanitary aspect, pests' occurrence, nutritional status, and other general aspects) in site visits, and, most importantly by a quantitative evaluation of the evolution and success of vegetative cover index throughout three years to access the long term erosion protection via permanent vegetation establishment. In this way, we intend to contribute to the knowledge building on using soil bioengineering techniques in Brazilian territory, possibly helping to broaden its use in the country.

\section{Methodology}

This study reports the application and monitoring of different bioengineering techniques for superficial slope erosion control and analyses the evolution of the vegetation developed in the slope surfaces evaluated. It is worth mentioning that the experimental units have been subjected only to the erosion process caused by the rainfall, which means the river was not in contact with any section of both experimental units (even during the flood seasons). The bioengineering techniques adopted, their application and monitoring, and procedures for determining the vegetative cover index are detailed as follows.

\subsection{Experimental Units}

Two slopes located on the Paraiba do Sul riverbanks, close to the Simplício Hydroeletric Power Plant (Chiador-MG in Brazil; Figure 1) were selected as experimental units in this study. In terms of the geology context, the experimental units are located on a Proerozoic gneiss-magmatic terrain (part of Juiz de Fora and Paraíba do Sul geological complexes), grouped in two lithological types: high-grade paragneisses and orthogneisses (dominant in the area of experiment).

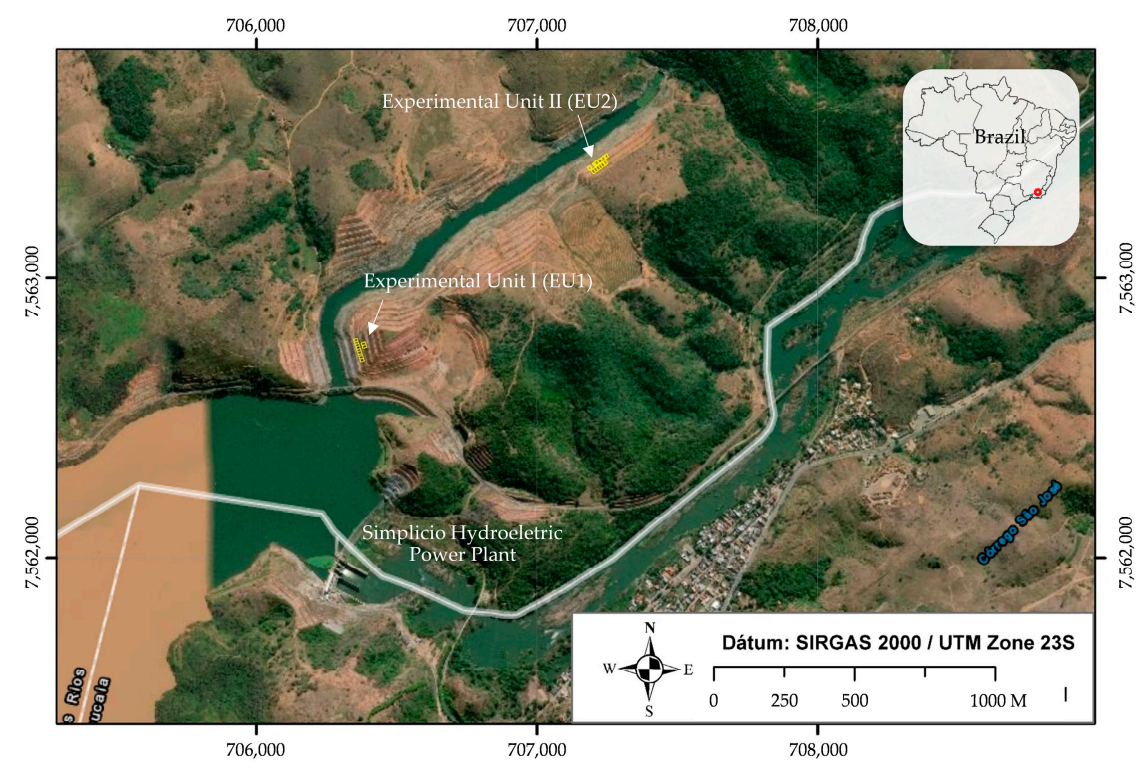

Figure 1. Location of the experimental units I (EU1; $22^{\circ} 1^{\prime} 40.06^{\prime \prime} \mathrm{S} ; 43^{\circ} 0^{\prime} 1.49^{\prime \prime} \mathrm{W}$ ) and II (EU2; $22^{\circ} 1^{\prime} 16.49^{\prime \prime}$ S; $42^{\circ} 59^{\prime} 30.36^{\prime \prime} \mathrm{W}$ ).

Experimental unit I (EU1) consists of two 90-m-long slopes (west facing slope) of approximately $9.5 \mathrm{~m}$ height $(\mathrm{H})$ and a slope angle $(\alpha)$ close to $32^{\circ}$, as indicated in Figure 2a. Similarly, the experimental unit II (EU2) consists of two 70-m-long slopes (northwest facing slope): the bottom one with $8.5 \mathrm{~m}$ height $(\mathrm{H})$ and $\alpha$ equal to $35^{\circ}$, and the upper one with $\mathrm{H}=9.5 \mathrm{~m}$ and $\alpha=32^{\circ}$ (Figure 2b). To avoid people traffic and animal trampling, the units were demarcated with fences (appropriate materials and equipment were used). The soil samples were collected $300 \mathrm{~mm}$ deep from the slopes' surfaces (15 m distant apart from each other) along both units (EU1 and EU2) to provide a representative 
characterization of its fertility. A total of 10 soil samples was tested for the unit EU1, whereas for the EU2, 6 soil samples were collected and tested. Following the test procedures recommended by the Brazilian Agricultural Research Corporation (EMBRAPA [35]), the soil fertility test results (Table 1; classification according to CFSEMG (1999)) indicate that the experimental units show similar fertility, with a low content for all parameters evaluated and medium acidity.

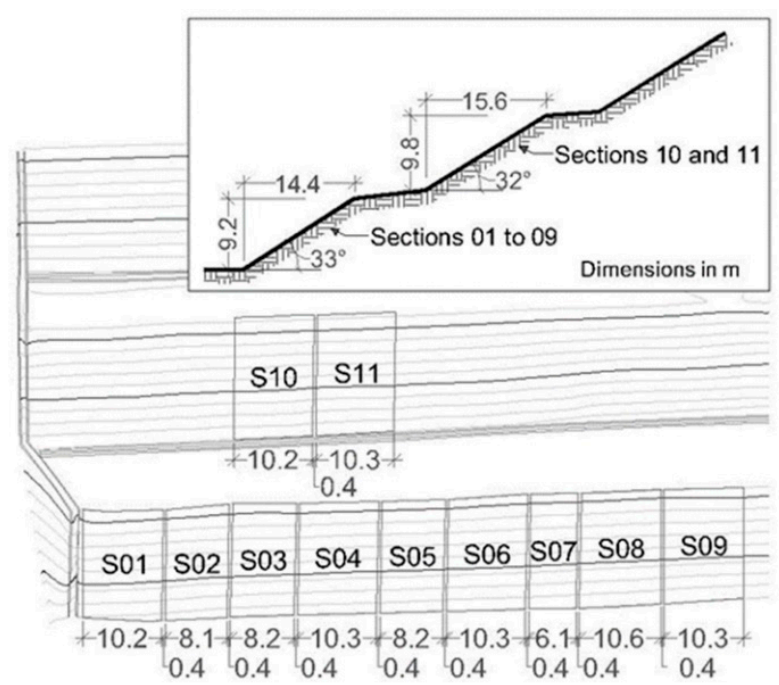

(a)

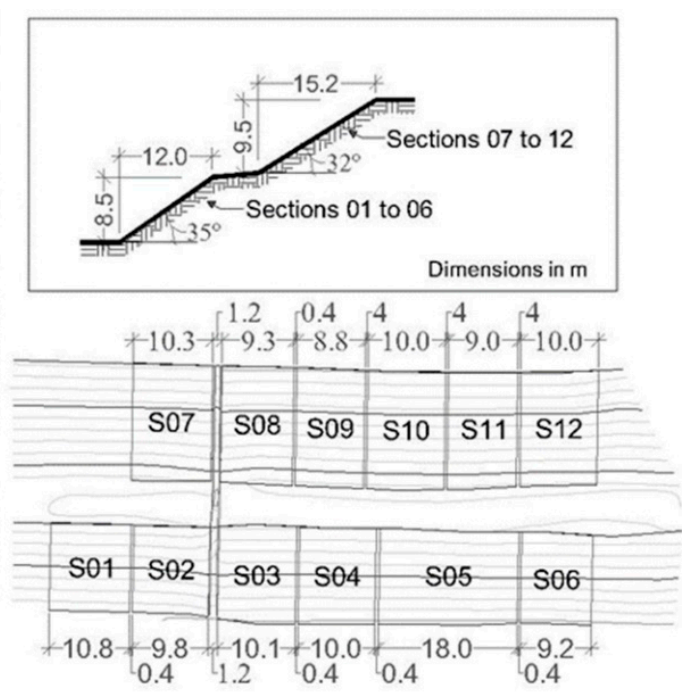

(b)

Figure 2. Topographic and division of the experimental units (a) I (EU1) and (b) II (EU2) into sections. [Note: Representative cross-sections are shown in the figure's upper region].

Additionally, Table 2 summarizes characterization and soil strength test results for the experimental units, performed based on the Brazilian Standard (NBR) proposed by the Brazilian Association of Technical Standards (ABNT). The laboratory tests consisted of specific gravity of soil solids (NBR 6458 [36]), grain size distribution (NBR 7181 [37]; classification according to American Society for Testing and Materials (ASTM; D 2487-06 [38]), Atterberg limits (NBR 6459 [39]; NBR 7180 [40]), standard Proctor compaction (NBR 7182 [41]), and a direct shear test (unsaturated soil samples compacted at similar density to the soil from the slopes; ASTM D 3080-98 [42]).

Prior to following the bioengineering techniques, the superficial soil of the slopes of the experimental units was prepared to provide an adequate slope (inclination) and condition for the execution process. The preparation included cleaning, removal of bulges and poorly consolidated soil masses, and manual conformation. Additionally, linear erosions (gullies and deep grooves) close to the experimental units that could impair this study were recovered using organic sediment.

Table 1. Soil fertility test results for the experimental units' slope surface (mean values from samples taken $30 \mathrm{~cm}$ deep from soil surface at 15-m linear intervals).

\begin{tabular}{|c|c|c|c|c|c|}
\hline \multirow{2}{*}{ Parameter } & \multirow{2}{*}{ Unit } & \multicolumn{2}{|c|}{ EU1 $^{a}$} & \multicolumn{2}{|c|}{ EU2 ${ }^{b}$} \\
\hline & & Value & Classification $^{\mathrm{c}}$ & Value & Classification $^{\mathrm{c}}$ \\
\hline $\mathrm{pH}$ & - & $5.8(0.2)$ & Medium acidity & $5.4(0.2)$ & Medium acidity \\
\hline Hydrogen $(\mathrm{H})^{d}$ & $\mathrm{meq} / 100 \mathrm{~cm}^{3}$ & $1.7(0.5)$ & - & $1.7(0.3)$ & - \\
\hline Aluminum $(\mathrm{Al})^{\mathrm{d}}$ & $\mathrm{meq} / 100 \mathrm{~cm}^{3}$ & $0.2(0.2)$ & Low & $0.6(0.4)$ & Medium \\
\hline Calcium (Ca) ${ }^{d}$ & $\mathrm{meq} / 100 \mathrm{~cm}^{3}$ & $1.1(0.8)$ & Low & $1.0(0.5)$ & Low \\
\hline Magnesium $(\mathrm{Mg})^{\mathrm{d}}$ & $\mathrm{meq} / 100 \mathrm{~cm}^{3}$ & $0.4(0.5)$ & Low & $0.2(0.2)$ & Low \\
\hline Phosphorus $(\mathrm{P})^{\mathrm{e}}$ & ppm & $2.3(2.5)$ & Low & $2.2(0.8)$ & Low \\
\hline Potassium (k) ${ }^{e}$ & ppm & $37.7(55.3)$ & Low & $19.7(17.3)$ & Low \\
\hline Organic matter (O.M.) & $\%$ & $0.10(0.14)$ & Low & $0.07(0.07)$ & Low \\
\hline
\end{tabular}

Note: standard deviation values are shown in parenthesis; ${ }^{a}$ ten soil samples tested; ${ }^{b}$ six soil samples tested;

${ }^{c}$ classification according to CFSEMG [43]; ${ }^{\mathrm{d}}$ exchangeable content; and ${ }^{\mathrm{e}}$ available content. 
Table 2. Geotechnical characteristics of the experimental units.

\begin{tabular}{ccc}
\hline Characteristic & Value & Standard \\
\hline Specific gravity of soil solids $\left(\rho_{s}\right)$ & $2.657 \mathrm{~g} / \mathrm{cm}^{3}$ & NBR 6458 [36] \\
Soil classification & Sandy silt $(\mathrm{ML})$ & NBR 7181 [37] \\
Liquid limit $(\mathrm{LL})$ & $44 \%$ & ASTM D 2487-06 [38] \\
Plastic limit (PL) & $27 \%$ & NBR 6459 [39] \\
Plasticity index $(\mathrm{PI})$ & $17 \%$ & NBR 7180 [40] \\
Maximum dry unit weight $\left(\gamma_{d \_m}\right)$ & $16.57 \mathrm{kN} / \mathrm{m}^{3}$ & - \\
Optimum water content $\left(w_{o p}\right)$ & $17.8^{3} \%$ & NBR 7182 [41] \\
Friction angle $(\varphi)$ & $33.9^{\circ}$ & NBR 7182 [41] \\
Cohesion $(c)$ & $16.54 \mathrm{kPa}$ & ASTM D 3080-98 a [42] \\
\hline
\end{tabular}

Note: ${ }^{\text {a }}$ Direct shear tests performed in unsaturated soil samples compacted at similar density to the soil from the slopes (normal stresses of 12.5, 25, 50, and $100 \mathrm{kPa}$ ).

Retainers (OSRs; 0.20 -m or 0.40-m width). OSRs consists of polypropylene screen coating filled with herbaceous straw or coconut fiber, prepared to become a suitable substrate for developing vegetation.

\subsection{Bioengineering Techniques}

This study assessed 12 different techniques: 6 isolated bioengineering techniques (IBT) and 6 mixed bioengineering techniques (MBT, more than one technique), both summarized in Table 3 . The techniques were chosen based on bibliographic research and consulting to specialized bioengineering companies (information of most common bioengineering techniques adopted in Brazil). The experimental units were divided into sections (EU1: S01 to S11; EU2: S01 to S14; dimensions indicated in Figure 2), and the bioengineering techniques were executed contiguously (randomly) along the experimental units (Figure 3) according to Table 3. A brief description of each technique is shown in the following table. Manual seeding was adopted as the control technique to evaluate the efficiency of the other techniques adopted herein. Manual seeding consists of the manual launch of seeds (species and quantity described in Table 4), and it was adopted in isolation conditions in EU1-S08 and EU2-S07 and in combination with organic sediment retainers (OSRs) in EU1-S06, EU1-S11, and EU2-S12. Manual seeding attached with organic material (cellulose mulch) was installed in EU1-S09 and in EU1-S10 (combined with OSRs) as an alternative to help germination and vegetation. The specimens presented in Table 4 were chosen based on bibliographic research, an indication of specialized Brazilian companies (including nurseries) and professors from Spellman College, California State University, Universidade Federal de Viçosa, and Universidade Federal de Minas Gerais.

Table 3. Bioengineering techniques evaluated and respective installation site-Experimental Unit (EU) and Section (S).

\begin{tabular}{lccc}
\hline \multirow{2}{*}{ Code } & Bioengineering Technique & \multicolumn{2}{c}{ Section Installed } \\
\cline { 3 - 4 } & EU1 & EU2 \\
\hline \multicolumn{2}{l}{ Isolated bioengineering techniques (IBT) } & S08 & S07 \\
\hline IBT-1 & Manual seeding & - & $\mathrm{S} 01$ \\
IBT-2 & Live stakes & - & $\mathrm{S} 06$ \\
IBT-3 & Live Organic Sediment Retainer (L-OSR) & $\mathrm{S} 01$ & $\mathrm{~S} 02 ; \mathrm{S} 03$ \\
IBT-4 & Live Rolled Erosion Control Products (L-RECPs) & $\mathrm{S} 02$ & \\
& Rolled Erosion Control Products (RECP-01) & $\mathrm{S} 11$ \\
IBT-5 & Rolled Erosion Control Products (RECP-02) & & $\mathrm{S} 09$ \\
& Rolled Erosion Control Products (RECP-03) & & $\mathrm{S} 07$ \\
IBT-6 & Geocellular containment system (GCSs) & $\mathrm{S} 05$ \\
\hline
\end{tabular}


Table 3. Cont

\begin{tabular}{|c|c|c|c|}
\hline \multirow{2}{*}{ Code } & \multirow{2}{*}{ Bioengineering Technique } & \multicolumn{2}{|c|}{ Section Installed } \\
\hline & & EU1 & EU2 \\
\hline \multicolumn{4}{|c|}{ Mixed bioengineering techniques (MBT) } \\
\hline MBT-1 & Manual seeding + Cellulose mulch & S09 & - \\
\hline MBT-2 & Manual seeding + Organic Sediment Retainer (OSR) & S06; S11 & S12 \\
\hline MBT-3 & $\begin{array}{c}\text { Manual seeding }+ \text { Cellulose mulch }+ \text { Organic Sediment } \\
\text { Retainer (OSR) }\end{array}$ & S10 & - \\
\hline MBT-4 & Live stakes + Live Organic Sediment Retainer (L-OSRs) & - & S04 \\
\hline MBT-5 & $\begin{array}{c}\text { Live stakes + Live Organic Sediment Retainer (L-OSRs) + } \\
\text { Manual seeding }\end{array}$ & S03; S04 & - \\
\hline \multirow[t]{2}{*}{ MBT-6 } & $\begin{array}{c}\text { Rolled Erosion Control Products (RECP-02) + Organic } \\
\text { Sediment Retainer (OSR) }\end{array}$ & S05 & S08; \\
\hline & $\begin{array}{c}\text { Rolled Erosion Control Products (RECP-03) + Organic } \\
\text { Sediment Retainer (OSR) }\end{array}$ & - & S10 \\
\hline
\end{tabular}

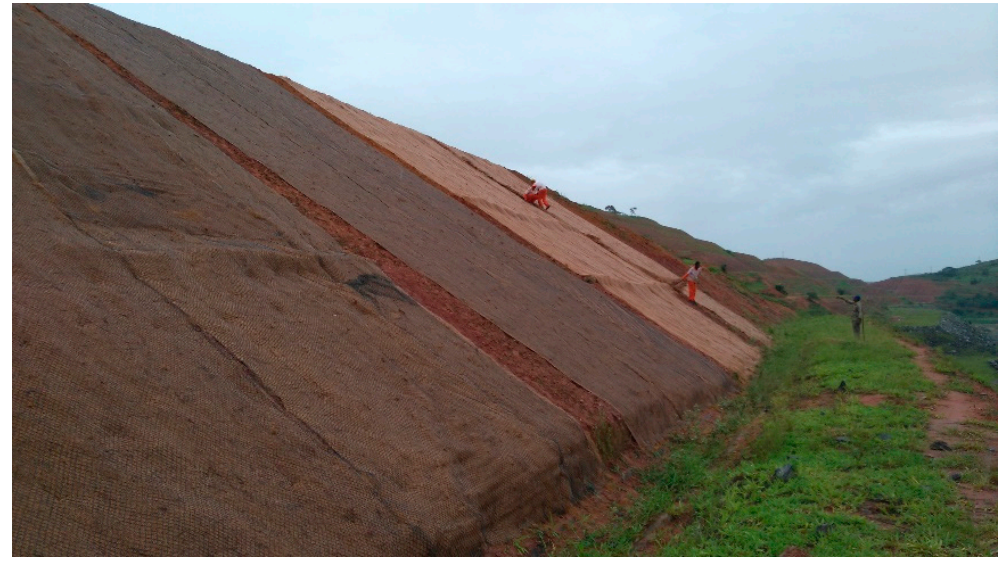

Figure 3. Contiguous execution of the bioengineering techniques with the experimental unit.

Table 4. Vegetative species (scientific and common name) adopted in bioengineering techniques.

\begin{tabular}{ccc}
\hline Scientific Name & Common Name $^{\text {a }}$ & Quantity $\left(\mathrm{g} / \mathbf{m}^{\mathbf{2}}\right)$ \\
\hline Alternanthera ficoidea $^{\mathrm{b}}$ & White carpet & 2.0 \\
Avena strigose $^{\mathrm{c}}$ & Black oats & 4.0 \\
Brachiaria humidicola $^{\mathrm{b}}$ & Koronivia grass & 2.5 \\
Brachiaria decumbens $^{\mathrm{b}}$ & Palisade grass & 2.5 \\
Hyparrhenia rufa $^{\mathrm{b}}$ & Jaragua grass & 2.5 \\
Lablab purpureus $^{\mathrm{b}}$ & Lab lab bean & 3.0 \\
Calopogonium mucunoides $^{\mathrm{d}}$ & Calopo & 1.5 \\
Melinis minutiflora $^{\mathrm{b}}$ & Molasses grass & 1.5 \\
Mucuna aterrima $^{\mathrm{b}}$ & Florida beans & 3.0 \\
Cajanus cajan $^{\mathrm{b}}$ & Pigean bean & 3.0 \\
\hline
\end{tabular}

Notes: ${ }^{a}$ The common names may depend on the region/country; ${ }^{\mathrm{b}}$ introduced species; ${ }^{\mathrm{c}}$ non-native species; and ${ }^{\mathrm{d}}$ native species.

Live and rootable vegetative cuttings, herein called "live stakes", were installed (tamped) into the ground of EU1-S01 in isolation conditions and in EU1-S03, EU1-S04, and EU2-S04 combined with organic sediment retainer (OSR). The live stakes were cultivated in greenhouses and treated with fungicidal solution (Benomyl, 0.03\%), nutritive fertilizer (Nitrogen $(\mathrm{N})$, Phosphorus $(\mathrm{P})$ and Potassium (K) (NPK) 20:20:20; $10 \mathrm{~g} / \mathrm{L}$ ), and rooting inductors (indole-butyric acid; $100 \mathrm{ppm}$ ). Live stakes were comprised by non-native (Eritrina mulungu, Croton urucurana, Hibiscus tiliaceus, Morus alba, Psidium guajava, Mimosa sp., Ficus gameleira, Joanesia princeps, Psidium cattleianum and Chorisia speciosa) 
and native (Hymenea corbaril, Caesalpinia leiostachya and Inga sp.) species. Images of the root system and installation procedures are available in Appendix A (Figure A1).

This study also investigated the adoption of flexible organic or synthetic rolls manufactured in greenhouses (live rolled erosion control products; L-RECPs). Structural geogrids (three-dimensional UV-stabilized polypropylene mesh) were layered in a levelled watertight surface followed by a layer of organic RECP. Over the RECPs surface, a mix of fast-growing herbaceous and legume seeds (indicated in Table $\left.4,10 \mathrm{~g} / \mathrm{m}^{2}\right)$, chemical fertilizer $\left(5 \mathrm{~g} / \mathrm{m}^{2}\right)$, organic compounds $\left(500 \mathrm{~g} / \mathrm{m}^{2}\right)$, and hydrogel $\left(5 \mathrm{~g} / \mathrm{m}^{2}\right)$ was spread. Finally, irrigation $\left(2-5 \mathrm{~L} / \mathrm{m}^{2}\right)$ was conducted at regular intervals. Images of L-RECPs storing and installation procedures are available in Appendix A (Figure A2). These elements were installed in isolation at EU1-S01, EU2-S02, and EU2-S03.

Live elements associated with organic sediment retainers (L-OSRs) were cultivated in greenhouses, with dimensions of $0.20 \times 2.00 \mathrm{~m}$ and $0.40 \times 1.60 \mathrm{~m}$ (diameter $\times$ length). They were installed in isolation (EU2-S06) and associated with live stakes (EU1-S03, EU1-S04, and EU2-S04). The seedlings were planted directly inside the OSR after making beds filled with $100 \mathrm{~g}$ of vermiculite associated with $2 \mathrm{~g}$ of hydrogel and $20 \mathrm{~g}$ of NPK 20:20:20 fertilizer powder. Images from the cultivation up to its installation are available in Appendix A (Figure A3).

This study also investigated the adoption of erosion control products commercially available in the Brazilian market. Three rolled erosion control products (RECPs) were adopted. The first one (RECP-01) is a coconut fiber blanket (mass per unit area $450 \mathrm{~g} / \mathrm{m}^{2}$ ) composed of a high flexible, UV-stabilized, and non-degradable three-dimensional polypropylene woven matrix, coupled with high resistance metallic hexagonal reinforcement mesh (installed in isolation in EU1-S02). The second RECP (RECP-02) is a two-dimensional erosion control blanket consisting of coconut fibers (mass per unit area $400 \mathrm{~g} / \mathrm{m}^{2}$ ) interlaced and incorporated in photodegradable polypropylene nets (installed in EU1-S05 and EU2-S08 in combination with OSR and in isolation in EU2-S11). Finally, the third RECP (RECP-03) is a straw erosion control blanket consisting of vegetable fibers (agricultural straw; mass per unit area $600 \mathrm{~g} / \mathrm{m}^{2}$ ) interlaced and incorporated in photodegradable polypropylene nets and a third UV-resistant net in the upper face (installed in isolation in EU2-S09 and combined with OSRs in EU2-S10).

An organic sediment retainer (OSR) manufactured using dehydrated vegetable fibers was combined with manual seeding in EU1-S06, EU1-S11, and EU2-S12 and further combined with cellulose mulch in EU1-S10. The experimental sections EU1-S05, EU1-S08, and EU2-S10 received a combination of OSR and rolled erosion control products (RECP). Additionally, a geocellular containment system (GCS) was adopted in sections EU1-S07 and EU2-S05. The GCSs are geobags (manufactured with a geosynthetic mesh of high-density polyethylene (HDPE) combined with an organic geotextile of coconut fiber) filled with herbaceous straw, organic matter, seeds, and fertilizers.

\subsection{Monitoring the Experimental Units}

Monitoring of the experimental unit sections started in December 2016 after completing the bioengineering techniques' implantation works. The monitoring occurred periodically, with 15-day interval visits in all units (i.e., EU1-S01 to EU1-S11 and EU2-S01 to EU2-S12) for the first 90 days after the implantation, followed by monthly visits up to 27 months after the works were finished. In this period, the sections were visited and detailed inspections were carried out using high-quality images taken from the front view of each section. During the visits, preventive and corrective actions were used to take care of leaf-cutting ants, leaf chlorosis, and fence conditions.

Furthermore, local qualitative analyses were conducted with evaluation cards (presented in Appendix B) to register integrity, anchoring, soil stability, germination, phytosanitary aspects, pests' occurrence, nutritional status, and other general aspects of the vegetation and/or bioengineering techniques in the experimental units' sections. Due to the existence of diagnostic (observer) bias in the set of characteristics evaluated, these results require a detailed analysis that may include the (observer) bias error and are not in the scope of this study. These qualitative results are aimed to be made available in future publications. 


\subsection{Vegetative Cover Index Determination}

The evolution of vegetative cover for each bioengineering technique adopted was evaluated by means of the vegetative cover index, calculated through a computer code in the MATLAB software (2015). The images captured (on a smartphone with wide-angle lens) during the experimental units' monitoring period (27 months; e.g., Figure $4 \mathrm{a}$ ) were treated and analyzed with a MATLAB script (or algorithm) developed using the method proposed by Woebbecke et al. [44]. This semi-quantitative analysis is proposed as an effective approach to assess the vegetation performance under climatological changes (dry and wet spell cycles).

Prior to its analysis, all images were treated by trimming out the regions outside the analyzed section area (Figure $4 \mathrm{~b}$ ). The MATLAB algorithm splits the image into three color bands (red, green, and blue-RGB scale). The value of each pixel was used to determine the normalized ratio of each color in the band by dividing it by 255 , which is the maximum value for each color, as shown in the following Equations (1)-(3):

$$
\begin{aligned}
& R^{*}=R / 255 \\
& G^{*}=G / 255 \\
& B^{*}=B / 255
\end{aligned}
$$

where $R^{*}, G^{*}$, and $B^{*}$ are the normalized ratio of red, green, and blue colors, respectively, and $R, G$, and $B$ are the color value of each pixel, which ranges from 0 to 255 , respectively.

The normalized colors were used to calculate the ratio of each color, $r, g$, and $b$, with respect to all three colors in the pixel, as shown in the Equations below (4)-(6):

$$
\begin{aligned}
& r=R^{*} /\left(R^{*}+G^{*}+B^{*}\right) \\
& g=G^{*} /\left(R^{*}+G^{*}+B^{*}\right) \\
& b=B^{*} /\left(R^{*}+G^{*}+B^{*}\right)
\end{aligned}
$$

Finally, the excess green $(E x G)$ value is calculated for each pixel using the Woebbecke et al. [45] excess green Equation (7):

$$
E x G=2 g-r-b
$$

The $E x G$ value for each pixel was compared to a minimum threshold value that was determined for each image. Thus, if the pixel's ExG value is greater than this threshold value, the pixel is set to represent vegetative covered areas (that means a vegetation pixel). The vegetative cover index is determined for each image by the ratio between the number of green pixels and the total number of pixels in the treated image (white pixels are not considered). In addition, the vegetation pixels were superimposed in the treated image for a visual comparison (Figure 4c).

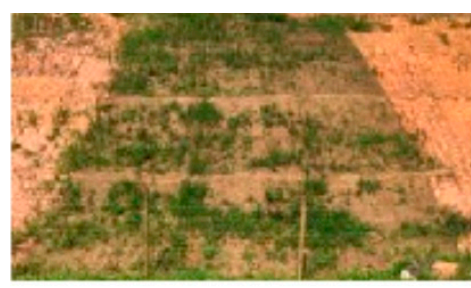

(a)

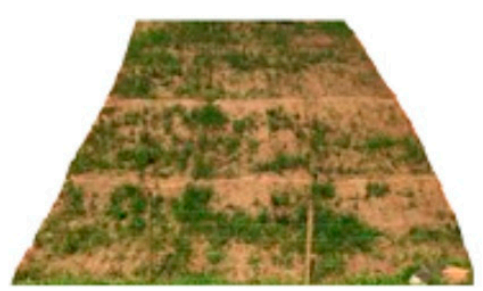

(b)

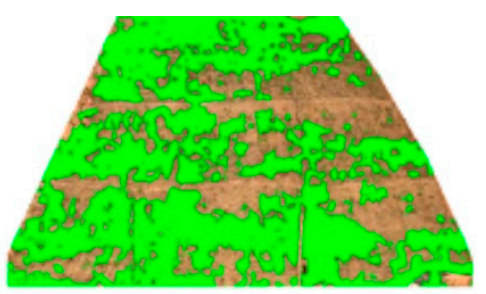

(c)

Figure 4. Image analysis processes: (a) original image; (b) treated image submitted to the computer algorithm; and (c) comparison between the vegetation pixels provided by the computer algorithm and the treated image. 
The vegetative cover index analysis was performed for all images taken while monitoring the experimental units (total of 601) for all sections, and bioengineering techniques were applied. The results were plotted in function of the time after the implanting the bioengineering works to evaluate the evolution of this parameter during the investigated period. In this study, vegetative cover index values higher than $70 \%$ are considered to represent a satisfactory superficial slope cover condition [45], in other words, to ensure the protection/control against erosion of the slope superficial soil.

\subsection{Climatological Data}

To compare the evolution of the vegetative cover index with the regional seasons, climatological data was obtained from the closest working weather station, $31 \mathrm{~km}$ from the experimental units. The precipitation data (in $\mathrm{mm}$ ), obtained with a rain gauge, are summarized in Figure 5 for the inspection period adopted herein. In summary, the local climatological condition is comprised of a rainy (wet) period during the spring and summer seasons and a dry period during the autumn and winter seasons.

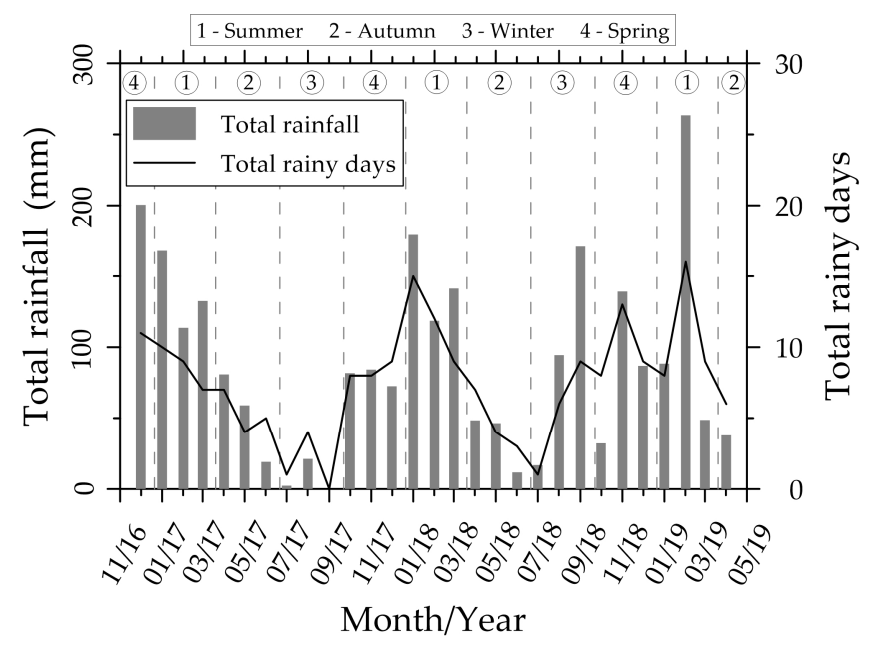

Figure 5. Total rainfall and number of rainy days obtained in a weather station located $31 \mathrm{~km}$ distant from the experimental units' location.

\section{Results and Discussion}

Figure 6 shows the vegetative cover index evolution for the bioengineering techniques installed in isolation at the experimental units. The vegetative cover index evolutions can be divided into five different groups. The first one exhibits vegetative cover index values lower than $40 \%$ (non-satisfactory values) during the whole period investigated. The index experienced small increases during the wet periods and remained or decreased during the dry ones. The manual seeding (IBT-1; EU1-S08 and EU2-S07), live stakes (IBT-2; EU2-S01), and live organic sediment retainer (L-OSRs; IBT-3; EU2-S06) techniques comprise this group (Figure 6a). The second group presented satisfactory vegetative cover index values (higher than 70\%) 25 days after it was implemented and small reductions at the end of the wet periods (especially the third period). Two techniques installed in the first experimental unit compose this group: live rolled erosion control products (L-RECPs; IBT-4; EU1-S01) and rolled erosion control product (RECP-01; IBT-5; EU1-S02).

The third group identified in Figure 6 comprises L-RECPs installed at the second experimental unit (IBT-4; EU2-S02 and EU2-S03) and the geocellular containment system (GCS) installed in EU1-S07. Similar to the second group, this group exhibited satisfactory vegetative cover index values very soon (25 days after its implementation). However, there was a significant reduction in the index values during the first dry period (softer reduction for the GCS-EU1-S07) followed by an increase in the following two periods, and a small reduction in the index values at the third wet period. RECPs installed in the second experimental unit (RECP-2 in EU2-S09 and RECP-03 in EU2-S11) are 
considered the fourth group and showed a high variation in the vegetative cover index values during the period investigated (increases in the wet periods and sharp decreases in the dry ones). A particular case in Figure 6 (the fifth group) is the GCS installed at EU2-S05 that started a significant increase in the vegetative cover index values at the middle of the first dry period and maintained a value close to $60 \%$ until the end of the investigated period.

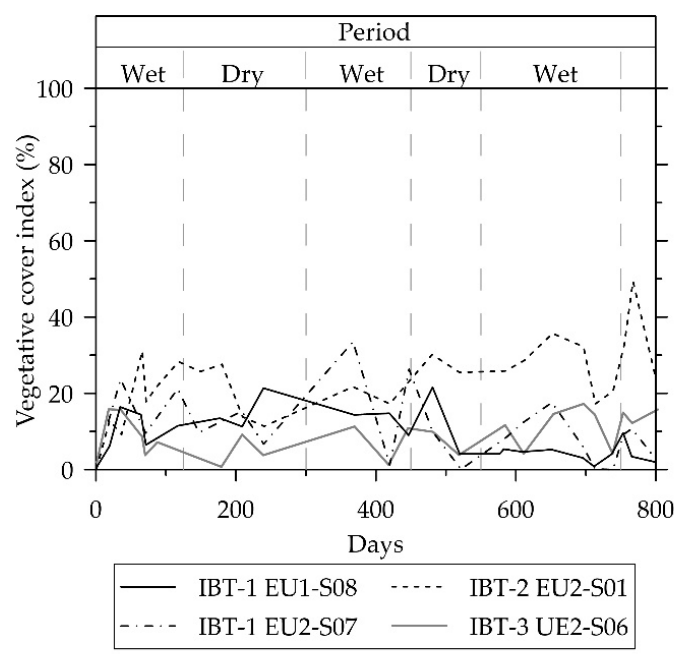

(a)

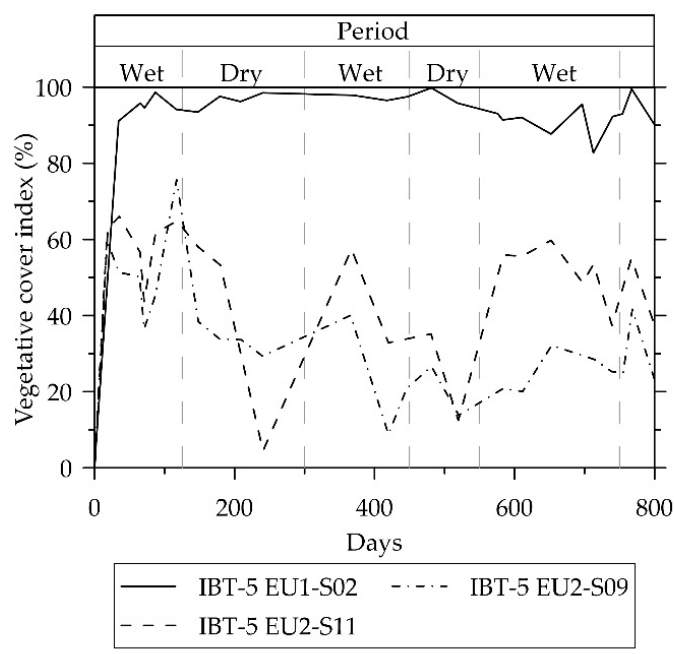

(c)

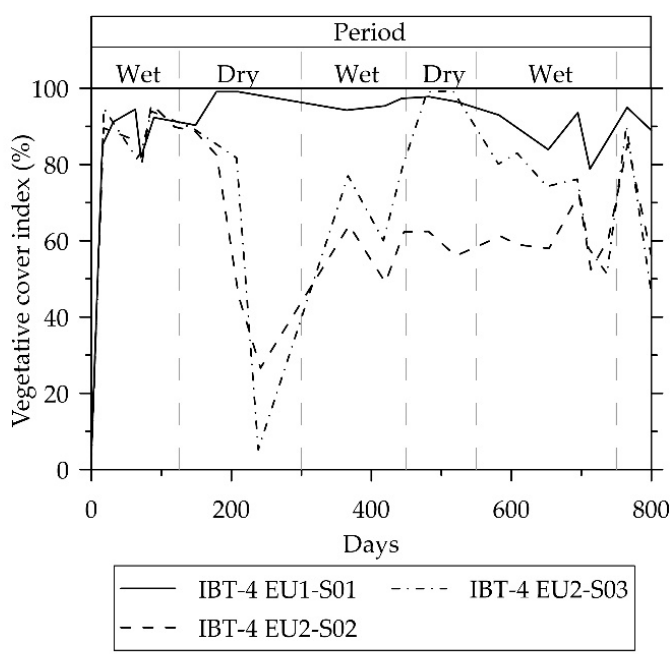

(b)

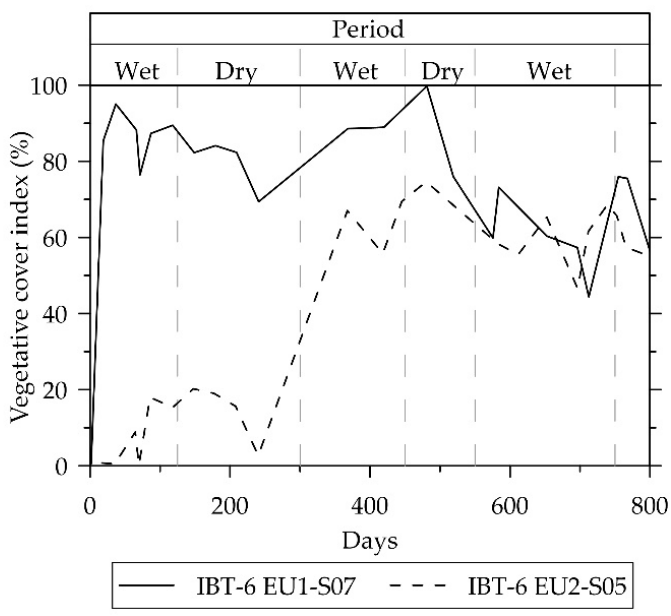

(d)

Figure 6. Vegetative cover index evolution for different in-isolation bioengineering techniques: (a) manual seeding (IBT-1; EU1-S08 and EU2-S07), live stakes (IBT-2; EU2-S01), and live organic sediment retainers (L-OSRs; IBT-3; EU2-S06); (b) live rolled erosion control products (L-RECPs; IBT-4; EU1-S01, EU2-S02, and EU2-S03); (c) rolled erosion control products (RECPs; IBT-5; EU1-S02, EU2-S09, and EU2-S110); and (d) geocellular containment system (GCSs; IBT-6; EU1-S07 and EU2-S05).

The results presented in Figure 6a indicate that the adoption of the in-isolation manual seeding technique (IBT-1) can be insufficient to prevent and control slope superficial soil erosion. Considering the vegetation establishment, difficulties can be observed since the first wet period, and it proves to be highly influenced by the changes in the climatological condition (especially during the dry periods). In addition, widespread laminar erosion and small grooves were reported in EU1-S08 at the end of the inspection period, proving the inefficiency of this technique.

Adopting live stakes in an isolated condition (IBT-2; EU2-S01) presented minimal effectiveness for the soil conditions and vegetation species used in this study. Three main factors impair its application: the values of the vegetative cover index for IBT-2 were slightly higher than the ones obtained with IBT-1 
(Figure 6a), the time consumed for the cultivation of the stakes, and the costs involved in the processes. Similarly, adopting live organic sediment retainers (L-OSRs) in isolation conditions (IBT-3; EU2-S06) proves to be inefficient. In fact, this technique (IBT-3) provided values of vegetative cover index smaller than the ones obtained with IBT-1 (Figure 6a).

Live rolled erosion control products (L-RECPs) installed in isolation (IBT-4; EU1-S01, EU2-S02 and EU2-S03) proved to be an attractive technique to prevent slope superficial erosion. However, for the sections of the second experimental unit (EU-2), sharp drops (dry periods or beginning of the wet periods) and sensitive reductions (especially during wet periods) characterize the evolution of vegetative cover index for this technique (Figure $6 b$ ).

Changes in the vegetation phytosanitary aspects (chlorosis and phytopathogen conditions) explain the sharp drops observed. The predecessor dry period could change the phytosanitary aspects of the vegetation, leading to an intensive decay of its green colors (becoming faded). Considering the computer code adopted in this study, when the treated image (containing faded vegetation) is subjected to the RGB scale, a decrease may occur in the pixel's green value, culminating in its identification as a pixel that does not represent vegetation, decreasing the vegetative cover index.

Considering the sensitive reductions, they can be attributed to the predominant vegetation composition (type). Some vegetative species may not adapt to the soil and/or climatological conditions (especially the non-native species), leading to changes in the vegetation phytosanitary aspects (initially) and/or the vegetation death. Further studies are required to validate this assumption and identify which species are unsuitable.

Three types of rolled erosion control products (RECPs) commercially available on the Brazilian market were installed in isolated conditions (IBT-5). RECP-01 (EU1-S02) exhibited a quick establishment of the vegetation-less than 30 days after it was implanted—and it has not been significantly influenced by climate changes (Figure 6c). Similar results were reported by Álvarez-Mozos et al. [46]. RECP-02 (EU2-S11) and RECP-03 (EU2-S09) also presented a quick establishment of the vegetation, but sharp drops and sensitive reductions in the vegetative cover index values are clear (Figure 6c).

Despite the similar behavior of the vegetative cover index evolution, RECP-02 exhibited a better re-establishment of the vegetation in the third wet period. Thus, one must consider that RECPs comprising coconut fibers could be more susceptible to vegetation development than the ones comprising vegetable fiber (straw). It is worth mentioning that these conclusions are specific for the conditions of soil and vegetation species used in this study. Furthermore, these products are indicated for temporary slope protection, as high degrees of deterioration were evident at the end of the inspection period-similar results were reported by Vishnudas [47].

Considering the last in-isolation technique investigated (IBT-6), the geocellular containment system (GCS) installed in EU1-S07 and EU2-S05 exhibited similar vegetation evolutions (Figure 6d). The non-satisfactory vegetative cover index values reported are associated with the difficulty of seeds' germination and establishment. The geotextiles act as a barrier between the seeds and the soil $[44,48]$ and between the sunlight and soil, leading to low germination rates [49]. However, the IBT-6 technique proved to avoid slope superficial erosion processes, as no erosive processes were reported during the inspections performed in the investigated period.

One must be aware of the shortcomings of comparing the performance of the in-isolation techniques in the experimental units one (EU-1) and two (EU-2). As shown by the results of the manual seeding (IBT-1; Figure 6a), L-RECPs (IBT-4; Figure 6b), and GCS (IBT-6; Figure 6d) techniques, differences in the vegetation development (and establishment) between sections installed in EU-1 and EU-2 were noted (especially in the dry periods). Overall, these results show that the sections of the second experimental unit (EU2) were more sensitive to climatological changes. In fact, because of the experimental units' different orientation (slope aspects stated in topic 2.1), the sections of EU2 face sunlight exposure for a longer period compared to the sections of EU1. This difference hampers the comparison between the results obtained with the RECPs' isolated technique (IBT-5, Figure $6 \mathrm{c}$ ). It is not ideal to compare the results obtained with RECP-01 with RECP-02 and/or RECP-03, because they 
were installed under the different experimental units and a different type of RECPs was adopted in each case.

Figure 7 shows the vegetative cover index evolution for the mixed bioengineering techniques installed at the experimental units. The vegetative cover index evolutions can be divided into three different groups. The first group exhibits vegetative cover index evolution similar to the first group of the in-isolation bioengineering techniques: unsatisfactory vegetative cover index values throughout the whole investigated period and increases during wet periods and maintenance or decrease of the index values during the dry periods. The manual seeding and cellulose mulch (MBT-1; EU1-S09), manual seeding and organic sediment retainers (OSRs; MBT-2; EU1-S06), and live stakes and live organic sediment retainer (L-OSRs; MBT-4; EU2-S04) techniques comprise this group. Manual seeding and ORSs (MBT-2; EU2-S12); live stakes, L-ORSs, and manual seeding (MBT-5; EU1-S04); and RECPs and OSRs (MBT-6; EU2-S10) techniques set the second group. This group is characterized by vegetative cover index values between 20 and $70 \%$, sharp drops in the index values at the end of the dry periods, and its increase during the wet ones.

Finally, the third group of mixed bioengineering techniques is characterized by a satisfactory vegetative cover index 30 days after the techniques were implemented, followed by variations (increases and decreases) in the index values for the whole period investigated (decreases occurred especially at the end of the periods-regardless of wet or dry ones). Despite this variability, the sections of this group exhibited a satisfactory vegetative cover index at the end of the investigation period. This group is comprised by manual seeding and ORSs (MBT-2; EU1-S11); manual seeding, cellulose mulch and OSRs (MBT-3; EU1-S10); live stakes, L-ORSs and manual seeding (MBT-5; EU1-S03); and rolled erosion control products (RECPs) and OSRs (MBT-6; EU1-S05 and EU2-S08).

The results presented in Figure 7a revealed that adopting organic material (cellulose mulch) attached with manual seeding (MBT-1) did not provide any improvement in the vegetation establishment compared with the in-isolation manual seeding technique (IBT-1; Figure 6a). In addition, widespread laminar erosion and small grooves were reported in the section (EU1-S09) at the end of the inspection period. Thus, adding organic material attached to the manual seeding technique does not seem to be an effective technique for the soil conditions studied in this paper. Further studies are required to assess other types of organic material attached to the manual seeding technique.

In the case of the combined adoption of organic sediment retainers (OSRs) and manual seeding technique (MBT-02), better establishment of the vegetation (Figure 7a) compared with IBT-1 (Figure 6a) is evident. However, MBT-2 exhibited high variability in the vegetative cover index evolution between the sections installed (EU1-S06, EU1-S11 and EU2-S12)—a notable difference occurs between EU1-S06 and EU1-S11, installed at the same experimental unit (EU1). Furthermore, this technique proved to be vulnerable to climatologic changes (dry-wet cycles) for the particular vegetation species used. Despite these issues, this mixed bioengineering technique prevented the occurrence of slope superficial erosion, as no erosion process was encountered in the sections up to the end of the investigation period. This evidence was expected, as the OSR decreases runoff on the slopes, retains humidity and nutrients in the system, and promotes vegetation establishment [50].

Despite the variability encountered for the aforementioned technique (MBT-2), the OSRs provided an excellent vegetation development when added to the manual seeding technique attached to organic material—cellulose mulch (MBT-3, EU1-S10; Figure 7a). MBT-3 proves to be an effective technique as slope superficial soil erosion protection.

The combination of live stakes (IBT-02) and L-OSRs (IBT-03) techniques (MBT-4; EU2-S04; Figure 7b) did not provide an improvement in the vegetation development compared to its in-isolation techniques (IBT-02 and IBT-03; Figure 6a). Despite the slight influence of the climatological condition in the vegetative cover index values, difficulties in the vegetation establishment occurred even during the wet period. Moreover, laminar erosion and grouting processes were reported during the inspections.

On the other hand, the combination of live stakes, live organic sediment retainers (L-OSRs), and manual seeding (MBT-5; EU1-S03 and EU1-S04) exhibited an improvement of the vegetation 
establishment (Figure 7) compared to its applications in isolation conditions (IBT-1, IBT-2, and IBT-3; Figure 6a). However, this technique exhibits an unexpected variability (MBT-5): vegetative cover index evolution between sections EU1-S03 and EU1-S04 is very different. As both sections are located side-by-side (Figure 2) and under identical climatological conditions, the difference in the vegetation evolution may be caused due to intrinsic variability of the technique-more than one material can contribute with its own variability.

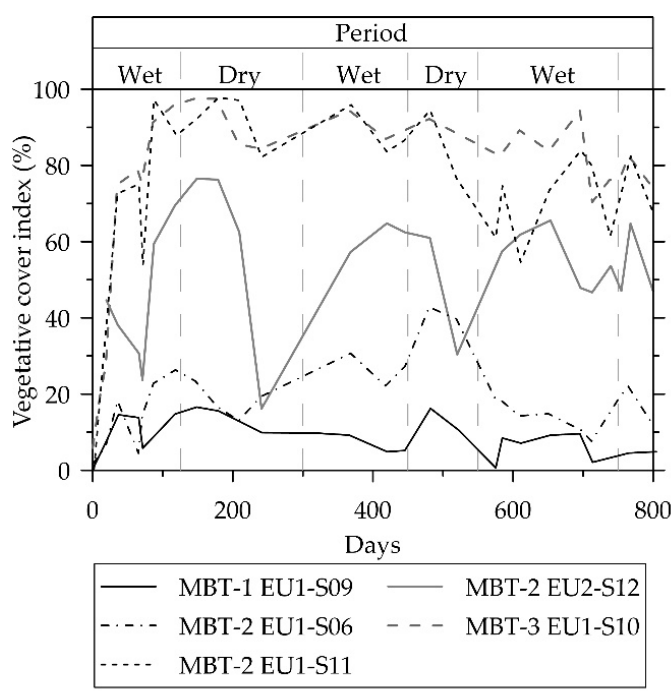

(a)

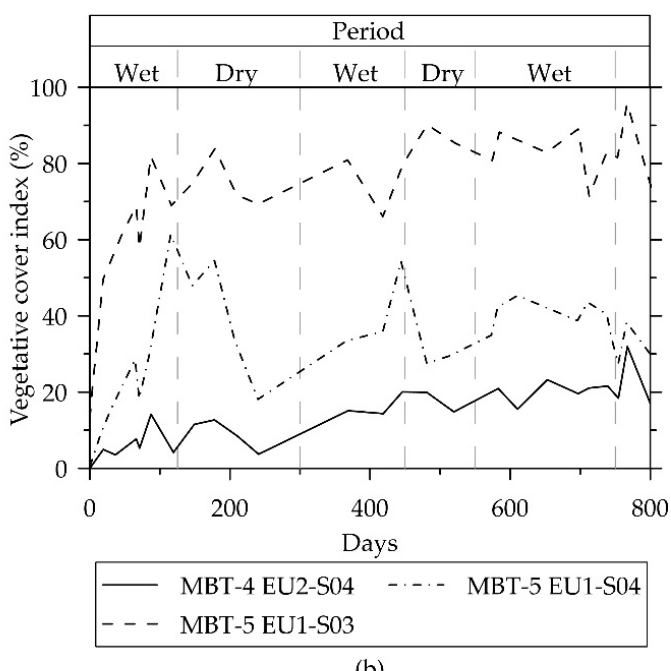

(b)

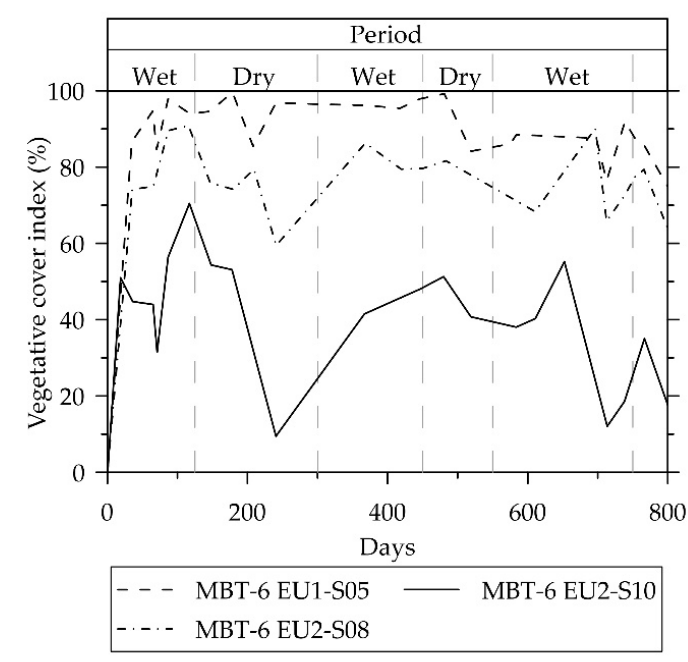

(c)

Figure 7. Vegetative cover index evolution for different mixed bioengineering techniques: (a) manual seeding and cellulose mulch (MBT-1; EU1-S09); manual seeding and organic sediment retainers (OSRs; MBT-2; EU1-S06, EU1-S11 and EU2-S12); and manual seeding, cellulose mulch and OSRs (MBT-3, EU1-S10); (b) live stakes and live organic sediment retainers (L-OSRs; MBT-4; EU2-S04) and live stakes, L-OSRs and manual seeding (MBT-5; EU1-S03 and EU1-S04); and (c) rolled erosion control products (RECPs; MBT-6; EU1-S05, EU2-S08, and EU2-S10).

Finally, the last mixed bioengineering technique (MBT-6) evaluated comprised the combination of RECPs and OSRs (Figure 7c). RECP-2 installed with OSRs (EU1-S05 and EU2-S08) exhibited better vegetation establishment, compared to RECP-3 installed with OSRs, during the whole period investigated (EU2-S10). Once again, the RECPs comprised by coconut fibers proves to be more susceptible for vegetation development than the ones comprised of vegetable fiber (straw) for similar conditions (soil and vegetation species used), as considered in this study. 
Differences between the vegetative cover index evolution between the same technique installed in both experimental unit sections were also evident in MBT-3 and MBT-6 (with RECP-2). These differences are related to the experimental units' different orientation (stated in topic 2.1) as previously discussed.

Despite the benefits of using geosynthetics (polymeric based materials) in geotechnical works, one must be aware of the long-term environmental impacts caused by using these materials. The small particles resulting from the geosynthetic degradation (micro plastic) may enter the environment, resulting in soil pollution and spoiling the fauna [48,51-53].

\section{Conclusions}

In this study, different types of bioengineering techniques were evaluated, in isolation and in combined conditions, as systems to prevent/control superficial erosion processes in the slopes of Paraíba do Sul-MG (Brazil). High-quality images taken from periodical visits conducted over the course of 27 months were submitted to a computer code to assess the percentage of vegetation developed in the slopes' superficial soil through time. Based on the results obtained in this study, the following conclusions can be drawn:

- Despite the similar characteristics of the soil of the two selected experimental units, the effectiveness of the same technique applied to both (EU1 and EU2) seems to be influenced by the differences in their climatological conditions. As the experimental units are only $1.2 \mathrm{~km}$ apart, differences in their climatological conditions can hardly be attributed to differences in rainfall events. Thus, due to the experimental units' different orientation, experimental unit two (EU2) was exposed to sunlight incidence for longer periods compared to experimental unit one (EU1). In this case, EU2 experienced significant changes in the vegetation's phytosanitary aspects, impairing the vegetative cover index's determination. This hypothesis is supported by the sharp drops in the vegetative cover index for most techniques at the end or after the dry periods in the EU2.

- Among the six in-isolation bioengineering techniques evaluated in this study, adopting manual seeding, live stakes, and live organic sediment retainers (L-OSRs) exhibited vegetative cover index values smaller than $40 \%$, with difficulties in vegetation establishment over the 27 -month investigated period (fluctuation in its values were also present). These techniques have not proven to be effective to prevent/control slopes' superficial erosion. Despite the high values of vegetative cover index observed when geocellular containment systems (GCSs) were applied, this technique exhibited fluctuation throughout the period investigated, which indicates vegetation establishment deficiency.

- Live rolled erosion control products (L-RECPs) and a highly flexible, UV-stabilized, and non-degradable three-dimensional matrix rolled erosion control product (RECP) investigated in isolation conditions exhibited a high tendency for vegetation development. L-RECPs led to a swift establishment of the vegetation. Adopting different types of RECPs available in the Brazilian market has shown that RECPs comprised of coconut fibers were more susceptible for vegetation development than the ones comprised of vegetable fiber (straw) for the specific soil conditions and vegetation species used herein. However, one must consider that for these techniques (L-RECPs and RECPs), the development of vegetation seems to be highly susceptible to harsh climatological conditions (especially the dry periods).

- Incorporating organic material (cellulose mulch) to the manual seeding technique did not improve the vegetation development. The inclusion of organic sediment retainers (OSR) to the manual seeding technique exhibited an expressive variability on the vegetative cover index, with a high influence of the dry periods in the vegetation establishment. However, the combination of manual seeding, cellulose mulch, and organic sediment retainers (OSR) proved to be an excellent technique, inducing a quick establishment of vegetation with satisfactory vegetative cover index and only slight fluctuations during the period investigated. Live stakes combined with organic sediment retainers (OSR) and the manual seeding technique exhibited high variability and non-satisfactory vegetative cover index. OSRs combined with commercially available RECPs exhibited a significant 
variability and proved to be sensitive in locations with a harsh climatological condition (especially the dry periods).

- The sharp drop and sensitive reductions in the vegetative cover index can be attributed to different factors. The sharp drops, especially at the end or after the exposure to dry periods, possibly occurred due to significant changes in the vegetation's phytosanitary aspect, in other words, an intensive decay on the vegetation's green color. Regarding the sensitive reductions in the vegetative cover index, especially in wet periods, they can be attributed to difficulties in some vegetative species (possibly the non-native ones) to adapt to the soil and/or climatological conditions of the area, resulting in a similar change in the vegetative phytosanitary aspects or vegetation death. In both cases, the reductions experienced in the vegetative cover index derive from the methodology adopted in this study, which did not include faded vegetation in the vegetative cover index. It should be noted that this conservative procedure aims to neglect the vegetation without adequate phytosanitary aspects, considering that they are not able to prevent the surface erosion of the slopes.

Finally, the conclusions presented in this study are restricted to the specific site-conditions investigated herein: the given slope, a sandy silt soil with low fertility and medium acidity in a tropical climate, and for the specific selected vegetation species used in the treatments. Therefore, caution should be exercised when using these conclusions for different site-conditions.

Author Contributions: The individual contributions of each authors are highlighted as follows: conceptualization: M.P.L.; data curation: M.P.F. and A.T.V.; formal analysis: M.P.F.; funding acquisition: M.P.L.; investigation: V.F.V. and G.B.M.; methodology: G.B.M.; project administration: M.P.L.; software: G.B.M. and A.T.C.; supervision: J.L.d.S.; validation: V.F.V.; visualization: C.B.; writing—original draft: M.P.F.; writing一review \& editing: C.B. and J.L.d.S. All authors have read and agreed to the published version of the manuscript.

Funding: This research was funded by the Agência Nacional de Energia Elétrica (ANEEL; PD-0394-1603/2016) and the Coordenação de Aperfeiçoamento de Pessoal de Nível Superior (CAPES; 001).

Acknowledgments: The authors would like to thank the University of São Paulo, California State University Los Angeles, and all of the Eletrobras FURNAS community for the support provided to the research activities reported in this paper and Agência Nacional de Energia Elétrica (ANEEL; National Agency of Electric Energy) for promoting this research to Bioengineering (PD-ANEEL number 0394-1603/2016). This study was financed in part (support granted to the second author) by the Brazilian Federal Agency for Support and Evaluation of Graduate Education (Coordenação de Aperfeiçoamento de Pessoal de Nível; CAPES)-Finance Code 001.

Conflicts of Interest: The authors declare that they have no known competing financial interests or personal relationships that could have appeared to influence the work reported in this paper. Thus, the authors declare no conflict of interest. Moreover, the funders had no role in the design of the study; in the collection, analyses, or interpretation of data; in the writing of the manuscript; or in the decision to publish the results.

\section{Appendix A}

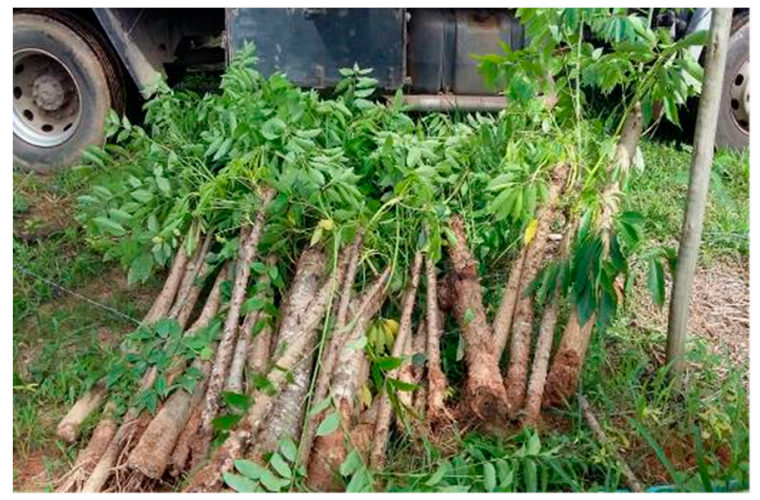

(a)

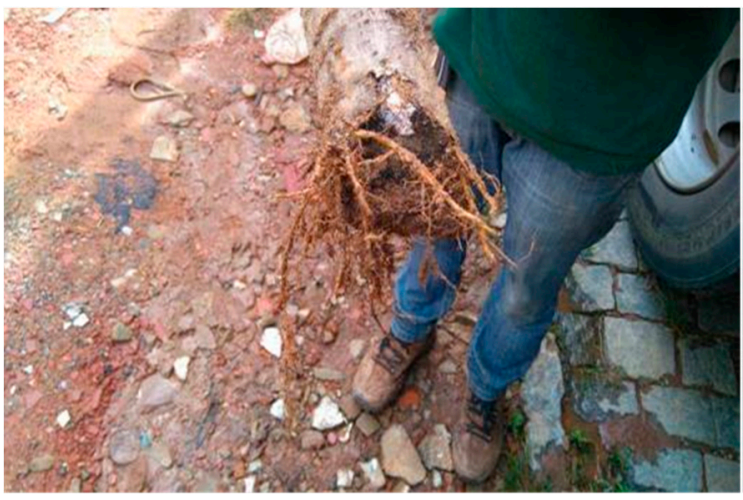

(b)

Figure A1. Cont. 


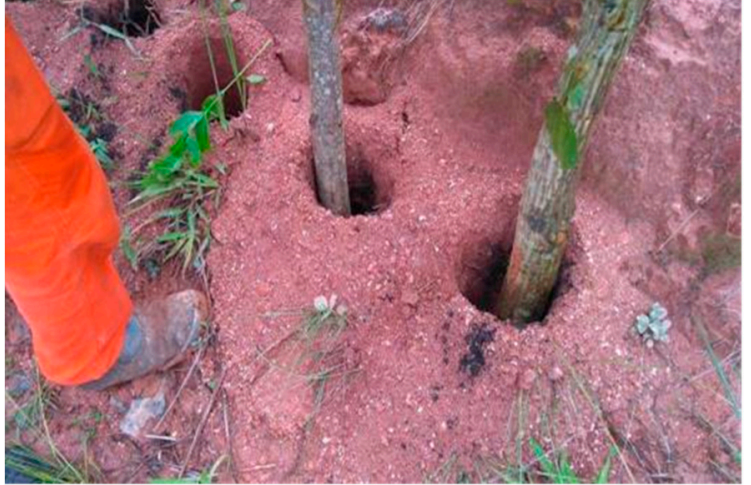

(c)



(d)

Figure A1. Live stakes: (a) storage after transport in an air-conditioned environment, (b) root system detail, (c) installation procedure in manually excavated cavities, and (d) substrate material application.

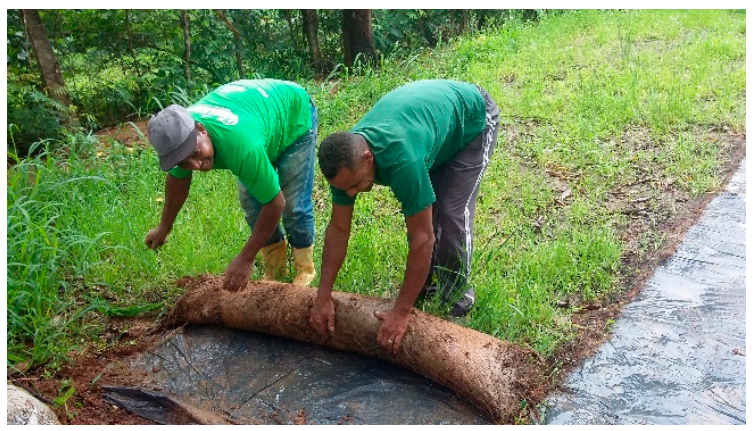

(a)

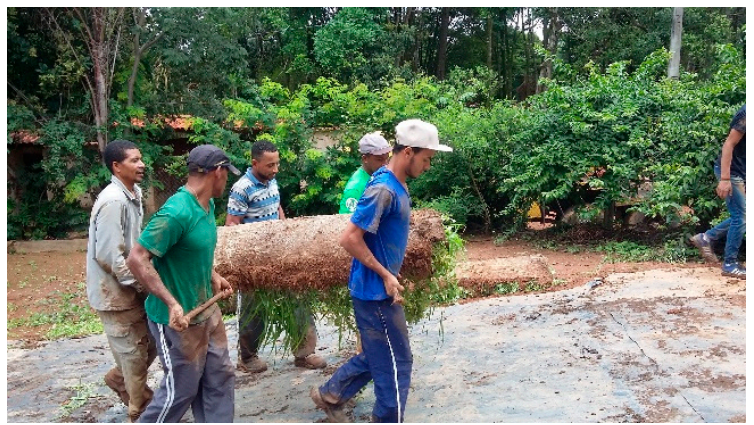

(c)

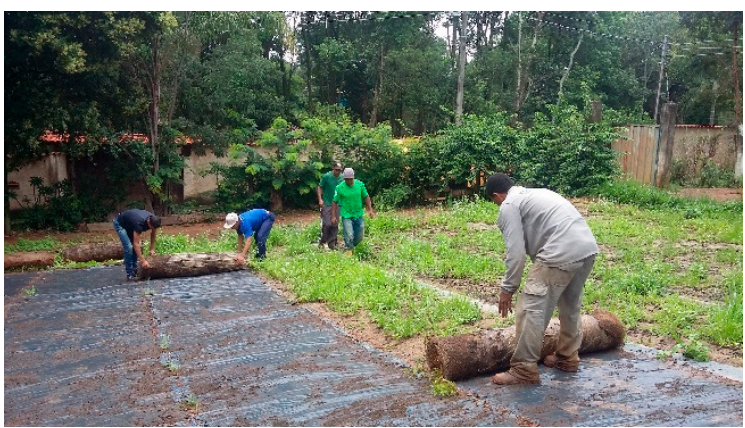

(b)

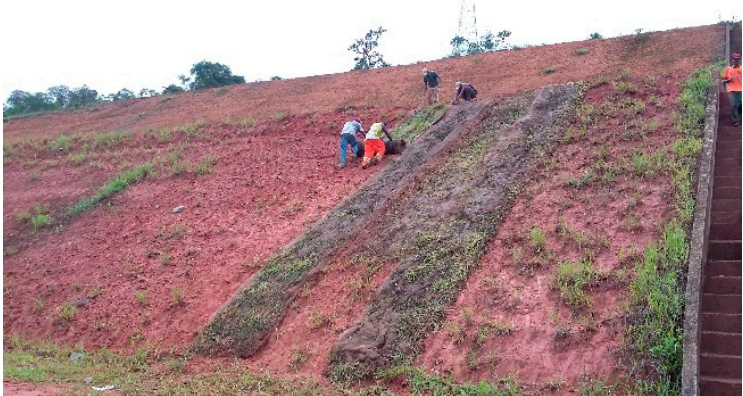

(d)

Figure A2. Live rolled erosion control products (L-RECPs): (a) cultivation at greenhouses, (b) coil-shaped collection, (c) transportation, and (d) installation of the elements in the experimental units slopes. 


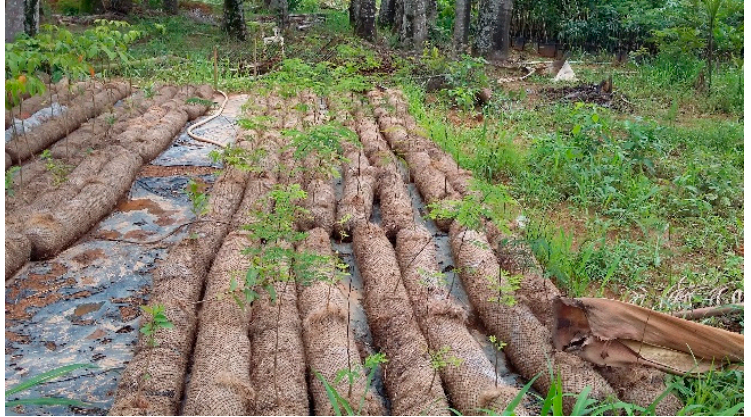

(a)

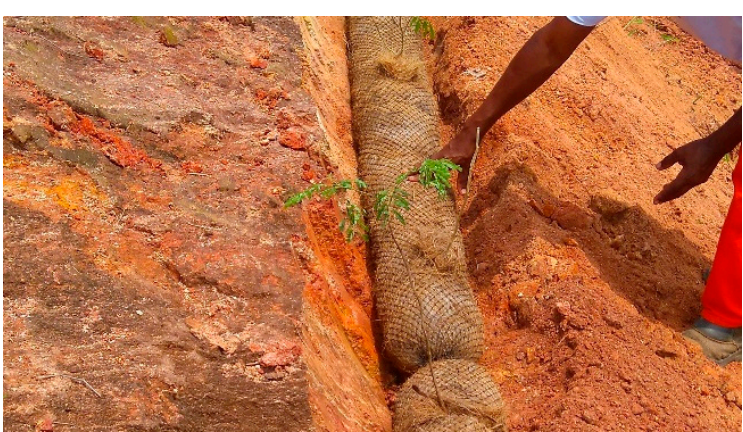

(b)

Figure A3. Organic sediment retainers associated with live elements (L-OSRs): (a) storage in the experimental units; and (b) installation of the elements in manually excavated trenches.

\section{Appendix B}

Table A1. Checklist for the visual inspections performed during visits carried out during 27 months in the experimental units' sections area.

\begin{tabular}{|c|c|}
\hline \multicolumn{2}{|r|}{ Inspection Check List of the Sections } \\
\hline Local: Simplício UHE & Experimental Unit: “Number of the EU” \\
\hline Section: "Number of the section" & Bioengineering technique: "Name of the bioengineering technique" \\
\hline Data: "Data of the inspection/visit" & Time: "Time of the inspection/visit" \\
\hline $\begin{array}{l}\text { Climatological Condition: "Sunny, } \\
\text { cloudy, partially cloudy, rainy" }\end{array}$ & $\begin{array}{l}\text { Data of the end of execution: "Data of the conclusion of the } \\
\text { bioengineering technique's execution process in the section" }\end{array}$ \\
\hline General aspects & $\begin{array}{l}\text { Good (Satisfactory general aspects) } \\
\text { Medium (Non-satisfactory factors present which does not compromise } \\
\text { the integrity and treatment efficiency) } \\
\text { Poor (Presence of non-satisfactory factors that may impair the integrity } \\
\text { and treatment efficiency) }\end{array}$ \\
\hline \multicolumn{2}{|r|}{ General aspects of the vegetation/structure } \\
\hline Structural integrity & $\begin{array}{l}\text { Good (Absence of apparent damage) } \\
\text { Medium (Presence of less significant damage) } \\
\text { Poor (Presence of damage that impairs the integrity and } \\
\text { treatment efficiency) }\end{array}$ \\
\hline Anchoring/Stapling & $\begin{array}{l}\text { Great (Efficient stapling, absence of loose or uprooted staples) } \\
\text { Good (Efficient stapling, presence of loose or uprooted staples in a rate up } \\
\text { to } 0.1 \text { staples } / \mathrm{m}^{2} \text { ) } \\
\text { Medium (Efficient stapling, presence of loose or uprooted staples in a rate } \\
\text { of } 0.1-0.5 \text { staples } / \mathrm{m}^{2} \text { ) } \\
\text { Poor (Efficient stapling, presence of loose or uprooted staples in a rate } \\
\text { higher than } 0.5 \text { staples } / \mathrm{m}^{2} \text { ) }\end{array}$ \\
\hline Soil stability/Erosion & $\begin{array}{l}\text { Good (general aspects of the section are satisfactory: without sediment } \\
\text { mobilization points) } \\
\text { Medium (section with the presence of sediment mobilization points); } \\
\text { Poor (presence of linear erosion) }\end{array}$ \\
\hline $\begin{array}{l}\text { Germination/Vegetation stakes } \\
\text { setting }(\%)\end{array}$ & $\begin{array}{l}\text { Good (Germination of } 25 \% \text { up to } 1 \text { month after cultivation or germination } \\
\text { of } 50 \% \text { for } 1-3 \text { months after cultivation or germination of } 70 \% \text { after } \\
3 \text { months of cultivation) } \\
\text { Medium (Germination of } 15 \% \text { up to } 1 \text { month after cultivation or } \\
\text { germination of } 30 \% \text { for } 1-3 \text { months after cultivation or germination of } \\
50 \% \text { after } 3 \text { months of cultivation) } \\
\text { Good (Germination less than } 25 \% \text { up to } 1 \text { month after cultivation or } \\
\text { germination less than } 30 \% \text { for } 1-3 \text { months after cultivation or germination } \\
\text { less than } 50 \% \text { after } 3 \text { months of cultivation) }\end{array}$ \\
\hline
\end{tabular}


Table A1. Cont.

\begin{tabular}{|c|c|}
\hline Predominant species & Mix of 10 herbaceous species (attached) \\
\hline Phytosanitary aspect & $\begin{array}{l}\text { Good (Absence of phytopathogen) } \\
\text { Medium (Presence of chlorosis and phytopathogen up to } 20 \% \text { of the } \\
\text { total vegetation) } \\
\text { Poor (Presence of chlorosis and phytopathogen higher than } 20 \% \text { of the } \\
\text { total vegetation) }\end{array}$ \\
\hline Pest occurrence & Presence or absence of pests \\
\hline Nutritional status & $\begin{array}{l}\text { Good (Absence of chlorosis in vegetation) } \\
\text { Medium (Occurrence of chlorosis up to } 20 \% \text { in the total vegetation) } \\
\text { Poor (Occurrence of chlorosis higher than } 20 \% \text { in the total vegetation) }\end{array}$ \\
\hline Fencing condition & $\begin{array}{l}\text { Good (Absence of fence breakage) } \\
\text { Poor (Presence of fence breakage) }\end{array}$ \\
\hline Additional aspects & Other aspects that must be highlighted \\
\hline \multicolumn{2}{|l|}{ Photographic report } \\
\hline Photo 01 & Photo 02 \\
\hline Photo 03 & Photo 04 \\
\hline
\end{tabular}

\section{References}

1. Ellison, W.D. Soil Erosion. Soil Sci. Soc. Am. J. 1948, 12, 479-484. [CrossRef]

2. Stokes, A.; Douglas, G.B.; Fourcaud, T.; Giadrossich, F.; Gillies, C.; Hubble, T.; Kim, J.H.; Loades, K.W.; Mao, Z.; McIvor, I.R.; et al. Ecological mitigation of hillslope instability: Ten key issues facing researchers and practitioners. Plant Soil 2014, 377, 1-23. Available online: http://link.springer.com/10.1007/s11104-014-2044-6 (accessed on 18 September 2020). [CrossRef]

3. Koerner, R.M. Emerging and Future Developments of Selected Geosynthetic Applications. J. Geotech. Geoenviron. Eng. 2000, 126, 293-306. [CrossRef]

4. Theisen, M. The role of geosynthetics in erosion and sediment control: An overview. Geotext. Geomembr. 1992, 11, 535-550. [CrossRef]

5. Bischetti, G.B.; Dio, M.D.F.; Florineth, F. On the Origin of Soil Bioengineering. Landsc. Res. 2012, 39, $583-595$. [CrossRef]

6. Gray, D.H.; Sotir, R.B. Biotechnical stabilization of steepened slopes. Transp. Res. Rec. 1995, 1474, 23-29. Available online: http://onlinepubs.trb.org/Onlinepubs/trr/1995/1474/1474-003.pdf (accessed on 18 September 2020).

7. Wu, K.; Austin, D. Three-dimensional polyethylene geocells for erosion control and channel linings. Geotext. Geomembr. 1992, 11, 611-620. [CrossRef]

8. Lewis, L.; Salisbury, S.L.; Hagen, S. Soil Bioengineering for Upland Slope Stabilization; Report WA-RD491.1; Washington State Transportation Center (TRAC): Washington, DC, USA, 2001.

9. Simon, K.; Steinemann, A. Soil Bioengineering: Challenges for Planning and Engineering. J. Urban Plan. Dev. 2000, 126, 89-102. [CrossRef]

10. Evette, A.; LaBonne, S.; Rey, F.; Liébault, F.; Jancke, O.; Girel, J. History of bioengineering techniques for erosion control in rivers in western europe. Environ. Manag. 2009, 43, 972-984. [CrossRef] [PubMed]

11. Stokes, A.; Raymond, P.; Polster, D.; Mitchell, S.J. Engineering the ecological mitigation of hillslope stability research into the scientific literature. Ecol. Eng. 2013, 61, 615-620. [CrossRef]

12. Stokes, A.; Sotir, R.; Chen, W.; Ghestem, M. Soil bio- and eco-engineering in China: Past experience and future priorities. Ecol. Eng. 2010, 36, 247-257. [CrossRef]

13. Rey, F.; Bifulco, C.; Bischetti, G.B.; Bourrier, F.; De Cesare, G.; Florineth, F.; Graf, F.; Marden, M.; Mickovski, S.; Phillips, C.; et al. Soil and water bioengineering: Practice and research needs for reconciling natural hazard control and ecological restoration. Sci. Total Environ. 2019, 648, 1210-1218. [CrossRef]

14. Lewis, L. Soil Bioengineering: An Alternative for Roadside A Practical Guide; San Dimas Technology \& Development Center: San Dimas, CA, USA, 2000.

15. Dhital, Y.P.; Tang, Q. Soil bioengineering application for flood hazard minimization in the foothills of Siwaliks, Nepal. Ecol. Eng. 2015, 74, 458-462. [CrossRef] 
16. Petrone, A.; Preti, F. Suitability of soil bioengineering techniques in Central America: A case study in Nicaragua. Hydrol. Earth Syst. Sci. 2008, 12, 1241-1248. [CrossRef]

17. Rauch, H.; Sutili, F.J.; Hörbinger, S. Installation of a Riparian Forest by Means of Soil Bio Engineering Techniques-Monitoring Results from a River Restoration Work in Southern Brazil. Open J. For. 2014, 4, 161-169. [CrossRef]

18. Woolsey, S.; Capelli, F.; Gonser, T.; Hoehn, E.; Hostmann, M.; Junker, B.; Paetzold, A.; Roulier, C.; Schweizer, S.; Tiegs, S.D.; et al. A strategy to assess river restoration success. Freshw. Biol. 2007, 52, 752-769. [CrossRef]

19. Hagen, S.; Salisbury, S.; Wierenga, M.; Xu, G.; Lewis, L. Soil Bioengineering as an Alternative for Roadside Management Benefit-Cost Analysis Case Study. Transp. Res. Rec. 2001, 1794, 97-104. [CrossRef]

20. Ghestem, M.; Cao, K.-F.; Ma, W.; Rowe, N.; Leclerc, R.; Gadenne, C.; Stokes, A. A Framework for Identifying Plant Species to Be Used as 'Ecological Engineers' for Fixing Soil on Unstable Slopes. PLoS ONE 2014, 9, e95876. [CrossRef]

21. Cazzuffi, D.; Cardile, G.; Gioffre, D. Geosynthetic Engineering and Vegetation Growth in Soil Reinforcement Applications. Transp. Infrastruct. Geotechnol. 2014, 1, 262-300. [CrossRef]

22. Stokes, A.; Atger, C.; Bengough, A.G.; Fourcaud, T.; Sidle, R.C.; Bengough, A.G. Desirable plant root traits for protecting natural and engineered slopes against landslides. Plant Soil 2009, 324, 1-30. [CrossRef]

23. Cavaillé, P.; Dommanget, F.; Daumergue, N.; Loucougaray, G.; Spiegelberger, T.; Tabacchi, E.; Evette, A. Biodiversity assessment following a naturality gradient of riverbank protection structures in French prealps rivers. Ecol. Eng. 2013, 53, 23-30. [CrossRef]

24. Tisserant, M.; Janssen, P.; Evette, A.; González, E.; Cavaillé, P.; Poulin, M. Diversity and succession of riparian plant communities along riverbanks bioengineered for erosion control: A case study in the foothills of the Alps and the Jura Mountains. Ecol. Eng. 2020, 152, 105880. [CrossRef]

25. Sotir, R.B. Integration of Soil Bioengineering Techniques for Watershed Management. In Wetlands Engineering and River Restoration Conference 2001; Intergovernmental Panel on Climate Change, Ed.; American Society of Civil Engineers (ASCE): Reston, VA, USA, 2001; pp. 1-8. Available online: https://www.cambridge.org/core/ product/identifier/CBO9781107415324A009/type/book_part (accessed on 18 September 2020).

26. Petrone, A.; Preti, F. Soil bioengineering for risk mitigation and environmental restoration in a humid tropical area. Hydrol. Earth Syst. Sci. 2010, 14, 239-250. [CrossRef]

27. Li, X.; Zhang, L.; Zhang, Z. Soil bioengineering and the ecological restoration of riverbanks at the Airport Town, Shanghai, China. Ecol. Eng. 2006, 26, 304-314. [CrossRef]

28. Zhang, H.-L.; Zhao, Z.; Ma, G.; Sun, L. Quantitative evaluation of soil anti-erodibility in riverbank slope remediated with nature-based soil bioengineering in Liaohe River, Northeast China. Ecol. Eng. 2020, 151, 105840. [CrossRef]

29. Von Der Thannen, M.; Hoerbinger, S.; Paratscha, R.; Smutny, R.; Lampalzer, T.; Strauss, A.; Rauch, H.P. Development of an environmental life cycle assessment model for soil bioengineering constructions. Eur. J. Environ. Civ. Eng. 2017, 24, 141-155. [CrossRef]

30. Sattler, D.; Seliger, R.; Nehren, U.; De Torres, F.N.; Da Silva, A.S.; Raedig, C.; Hissa, H.R.; Heinrich, J.; Filho, W.L.; De Freitas, L.E. Pasture Degradation in South East Brazil: Status, Drivers and Options for Sustainable Land Use under Climate Change. In Climate Change Adaptation in Latin America Managing Vulnerability, Fostering Resilience; Filho, W.L., de Freitas, L.E., Eds.; Springer: Berlin/Heidelberg, Germany, 2017; pp. 3-17.

31. Sattler, D.; Raedig, C.; Hebner, A.; Wesenberg, J. Use of Native Plant Species for Ecological Restoration and Rehabilitation Measures in Southeast Brazil. In Strategies and Tools for a Sustainable Rural Rio de Janeiro; Springer: Berlin/Heidelberg, Germany, 2018; pp. 191-204.

32. Rey, F.; LaBonne, S. Resprout and Survival of Willow (Salix) Cuttings on Bioengineering Structures in Actively Eroding Gullies in Marls in a Mountainous Mediterranean Climate: A Large-Scale Experiment in the Francon Catchment (Southern Alps, France). Environ. Manag. 2015, 56, 971-983. [CrossRef]

33. Muhammad, M.M.; Alias, M.N.; Yusouf, K.W.; Mustafa, M.U.; Ghani, A.A. Suitability of bioengineering channels in erosion control: Application to urban stormwater drainage systems. Adv. Appl. Fluid Mech. 2016, 19, 765-785. [CrossRef]

34. Giupponi, L.; Borgonovo, G.; Giorgi, A.; Bischetti, G.B. How to renew soil bioengineering for slope stabilization: Some proposals. Landsc. Ecol. Eng. 2018, 15, 37-50. [CrossRef] 
35. Donagema, G.K.; Campos, D.V.B.; Calderano, S.B.; Teixeira, W.G.; Viana, J.H.M. Soil Analysis Methods Manual, 2nd ed.; Brazilian Agricultural Research Corporation (EMBRAPA): Rio de Janeiro, Brazil, 2011; p. 230. Available online: https://www.embrapa.br/busca-de-publicacoes/-/publicacao/990374/manual-de-metodosde-analise-de-solo (accessed on 18 September 2020).

36. Brazilian Association of Technical Standards. NBR 6458: Gravel Grains Retained on the 4,8 mm Mesh Sieve-Determination of the Bulk Specific Gravity, of the Apparent Specific Gravity and of Water Absorption; ABNT: Rio de Janeiro, Brazil, 2016; p. 14.

37. Brazilian Association of Technical Standards. NBR 7181: Soil—Grain Size Analysis; ABNT: Rio de Janeiro, Brazil, 2016; p. 16.

38. American Society for Testing and Materials. ASTM D 2487-06: Standard Practice for Classification of Soils for Engineering Purposes (Unified Soil Classification System); ASTM International: West Conshohocken, PA, USA, 2006; p. 12.

39. Brazilian Association of Technical Standards. NBR 6459: Soil—Liquid Limit Determination; ABNT: Rio de Janeiro, Brazil, 2016; p. 9.

40. Brazilian Association of Technical Standards. NBR 7180: Soil_Plasticity Limit Determination; ABNT: Rio de Janeiro, Brazil, 2016; p. 7.

41. Brazilian Association of Technical Standards. NBR 7182: Soil—Compaction Test; ABNT: Rio de Janeiro, Brazil, 2016; p. 13.

42. American Society for Testing and Materials. ASTM D 3080-98: Standard Test Method for Direct Shear Test of Soils under Consolidated Drained Conditions; ASTM International: West Conshohocken, PA, USA, 1998; p. 6.

43. Soil Fertility Commission of the State of Minas Gerais. Recommendations for Use of Fertilizer Correctives in Minas Gerais, 5th ed.; Ribeiro, A.H.A., Guimarães, P.T.G., Alvarez, V.H., Eds.; CFSEMG: Viçosa, MG, Brazil, 1999 ; p. 359.

44. Woebbecke, D.M.; Meyer, G.E.; Von Bargen, K.; Mortensen, D.A. Color Indices for Weed Identification Under Various Soil, Residue, and Lighting Conditions. Trans. ASAE 1995, 38, 259-269. [CrossRef]

45. Coppin, N.J.; Richards, I.G. Use of Vegetation in Civil Engineering; Coppin, N.J., Richards, I.G., Eds.; Construction Industry Research and Information Association (CIRIA): London, UK, 1990; p. 40.

46. Álvarez-Mozos, J.; Abad, E.; Goñi, M.; Giménez, R.; Campo, M.A.; Díez, J.; Casalí, J.; Arive, M.; Diego, I. Catena Evaluation of erosion control geotextiles on steep slopes. Part 2: In fl uence on the establishment and growth of vegetation. Catena 2014, 121, 195-203. [CrossRef]

47. Vishnudas, S.; Savenije, H.; Van Der Zaag, P.; Anil, K.R.; Balan, K. The protective and attractive covering of a vegetated embankment using coir geotextiles. Hydrol. Earth Syst. Sci. 2006, 10, 565-574. [CrossRef]

48. Wiewel, B.V.; Lamoree, M. Geotextile composition, application and ecotoxicology-A review. J. Hazard. Mater. 2016, 317, 640-655. [CrossRef] [PubMed]

49. Chen, S.-C.; Chang, K.-T.; Wang, S.-H.; Lin, J.-Y. The efficiency of artificial materials used for erosion control on steep slopes. Environ. Earth Sci. 2010, 62, 197-206. [CrossRef]

50. Olsen, M.J.; Rikli, A.M. Investigation of Straw Wattle Influence on Surficial Slope Stability. In Proceedings of the Transportation Research Board 91st Annual Meeting, Washington, DC, USA, 22-26 January 2012; p. 16.

51. Hsuan, Y.G.; Schroeder, H.F.; Rowe, K.; Muller, W.; Greenwood, J.; Cazzuffi, D.; Koerner, R.M. Long-term performance and lifetime predition of geosynthetics. In Proceedings of the 4th European Conference on Geosynthetics, Edinburgh, Scotland, UK, 7-10 September 2008; p. 40.

52. Prambauer, M.; Wendeler, C.; Weitzenböck, J.; Burgstaller, C. Geotextiles and Geomembranes Biodegradable geotextiles-An overview of existing and potential materials. Geotext Geomembranes. Geotext. Geomembr. 2019, 47, 48-59. [CrossRef]

53. Browne, M.A.; Galloway, T.; Thompson, R.; Chapman, P.M. Microplastic-An emergig contaminant of potential concern? Integr. Environ. Assess Manag. 2007, 3, 559-561. [CrossRef]

(C) 2020 by the authors. Licensee MDPI, Basel, Switzerland. This article is an open access article distributed under the terms and conditions of the Creative Commons Attribution (CC BY) license (http://creativecommons.org/licenses/by/4.0/). 